\title{
İtalyan gerçekçiliğinin temsilcisi Giovanni Verga'nın "Nedda” adlı öyküsünde ölüm ve kader kavramlarının incelenmesi
}

Ebru BALAMÍR

\begin{abstract}
APA: Balamir, E. (2019). İtalyan gerçekçiliğinin temsilcisi Giovanni Verga’nın "Nedda” adlı öyküsünde ölüm ve kader kavramlarının incelenmesi. RumeliDE Dil ve Edebiyat Araştırmaları Dergisi, (17), 428-435. DOI: 10.29000/rumelide.657921
\end{abstract}

\section{$\ddot{\mathbf{O} z}$}

1840 yılında İtalya'nın Sicilya adasında dünyaya gelen Giovanni Verga, doğduğu bölgedeki yaşam koşullarını, bölge insanlarının yoksulluğunu ve bu yaşam koşullarına boyun eğişlerini ele alan bir yazar olmuştur. Yazar bölgedeki güç ve acı dolu, dürüst ve sade yaşamlarda kendine esin kaynağ bulmaya çabalamıştır. Tüm bu örnekler karşısında Verga'nın yazdığı ilk gerçekçi öykülerinden biri sayllabilen "Nedda"dır. Öykünün başkahramanı olan Nedda, yoksul ve kaderine boyun eğmeye alışmış bir genç kızdır. Hasta bir annesi olan Nedda, onun ilaç masraflarını karşılamak için uzaklara çalışmaya gider, hafta sonu eve döndüğünde ise annesini kaybeder. Onun ölümü ile acılarından kurtulduğunu düşünen Nedda teselli bulur; geçinmek için çalışmaya devam eder. Bu kez Janu adlı bir gençle tanışır, evlenmeden hamile kalır, Janu'nun da sıtmadan ölmesi Nedda'yı derinden etkiler, yapayalnız kalmış ve evlilik dışı çocuk dünyaya getireceğinden toplumdan dışlanmıştır, çelimsiz bir bebek dünyaya getirir, ancak maddi koşullarının yetersizliği nedeniyle bebeği gerektiği gibi besleyemez ve onu da kaybeder. Nedda adeta onun ölümüne sevinir, kendisi gibi acı içerisinde yaşamasını istemez, bu yüzden bu kaderinden ötürü Tanrı’ya şükreder. Yaşam acı çekmekten ibarettir, ölüm ise bu acı ve yoksulluktan kurtulmak anlamına gelir. Bu çalışmada Verga'nın bu öyküsünde ‘ölüm’ ve 'kader’ kavramlarını nasıl ele aldığı örneklendirmelerle irdelenmiştir.

Anahtar kelimeler: Verga, öykü, ölüm, kader, gerçekçilik.

\section{The research of the terms of 'death' and 'destiny' in the story named "Nedda" of Giovanni Verga, the representative of Italian realism}

\begin{abstract}
Verga, born in Sicily in 1840, is one of the most important writers that contributes to the nativity and progress of Verism in Italy observing Sicily's people, their life, the conditions and the misery of them. He wants to find an inspiration in their honest and pure life. One of the most realist stories of Verga is "Nedda". Nedda, the protagonist of the story, is a poor girl that surrenders always to her destiny. To find the money required for the medicines of her ill mother she goes to work far away. When she turns back, soon her mother dies. She feels grateful about her death because she thinks that her mother is safe now and she won't have to work for her. As she continues to work for herself, she falls in love with Janu, a young poor boy and gets pregnant. But Janu is ill. Just before they get married, one day while he's working, he dies because of malaria. Nedda is all alone now, she gives birth but because of misery she can't feed enough her baby that also dies in a few days. Nedda is grateful again for this lost also, she doesn't want her baby to suffer in misery like herself. For Nedda life means
\end{abstract}

1 Dr. Öğr. Üyesi, Ankara Üniversitesi, Dil ve Tarih-Coğrafya Fakültesi, Batı Dilleri ve Edebiyatları (Ankara, Türkiye), balamir@ankara.edu.tr, ORCID ID: 00oo-0oo1-6669-914X [Makale kaylt tarihi: 20.08.2019-kabul tarihi: 20.12.2019; DOI: $10.29000 /$ rumelide.657921] 
suffering and death is the only way to get rid of this pain and misery. The aim of this study is to research with examples the terms of 'death' and 'destiny' in Verga's story named "Nedda".

Keywords: Verga, story, death, destiny, realism.

\section{Giriş}

$\mathrm{Bu}$ çalışmamızın konusu 1840 yılında İtalya'nın Sicilya adasında dünyaya gelen Giovanni Verga adlı yazarın edebi yaşantısı boyunca savunduğu İtalyan gerçekçiliği yani verizm doğrultusunda yazdığı ve görüşlerini ilk dile getirdiği yapıtı olan "Nedda" adlı öyküsünde özellikle karşımıza çıkan iki temel kavramıdır.

Bu iki temel kavramdan ilki 'kader' kavramıdır. İtalyan gerçekçiliğinin en büyük temsilcisi olan yazarın bu öyküsü başta olmak üzere özellikle iki büyük romanında da karşımıza çıkan kader kavramı, döneminin yoksul Güney İtalya halkının yaşamlarının en önemli parçası sayılabilir. Yoksulluğun bu insanları kaderci yaptığı gerçeği verist yazarların özellikle dile getirdiği bir durumdur. Yaşantıları boyunca başlarına gelebilecek her tür felaketi kader ile bağdaştıran bu insanlar, Verga'nın bir çok eserinin konusu olmuştur.

Makalemizde irdeleyeceğimiz ikinci kavram ise ‘ölüm’dür. Ölüm de yine yazarımızın bu yapıtının başkahramanı Nedda'nın yazgısının bir parçası olarak karşımıza çıkar. Yoksul kızın yaşadığı birçok felaketin bir kısmını sevdiklerinin yitirilmesi oluşturmaktadır. Sevdiklerinin ölümüne dahi sevinen Nedda, yazarın bu insanların ölüme birer kurtuluş gözüyle baktıklarını anlatır niteliktedir. Bu bakış açısı yazarın "Malavoglia'lar” ve "Mastro Don Gesualdo" gibi başyapıtlarında da karşımıza çıkacaktır.

Kendi doğup büyüdügü yöreyi ve insanlarını çok iyi gözlemleyebilmiş olan yazarın kahramanları ekonomik sıkıntılar içerisindedir. Verdikleri hayat mücadelesini acımasızca anlatan yazar onların hayatlarına müdahale etmekten kaçınır, duygusal davranmaz. "Nedda"da olduğu gibi diğer yapıtlarındaki kahramanlar için yaşam acı çekmekten ibarettir, ölüm de tüm bu acılardan kurtulmaktır. $\mathrm{Bu}$ çalışmada öncelikle yer vermek istediğimiz yazarın verizmle tanışmasının ardından kaleme aldığı “Nedda” adlı gerçekçi öğeler içeren öyküsünde 'kader' ve 'ölüm' kavramlarıdır. Kaderine boyun eğmekten başka çaresi olmayan yoksul Nedda'nın güçlükler karşısındaki kaderci tutumu ve ölüme olan bakışı örneklerle yazımızda yer alacaktır. Yazarın bu öyküsünü ve öyküsünde karşımıza çıkan iki temel kavramı incelemeden önce, Verga'nın yaşantısına ve İtalyan gerçekçiliğini nasıl benimsediğine bir göz atmak gerekir.

\section{Verga ve İtalyan gerçekçiliği}

İtalya'da 19. Yüzyılın sonlarında İtalyan Gerçekçiliği olarak gelişen Verizm akımının baş temsilcisi sayılabilecek olan Giovanni Verga 1840 yılında Catania'da dünyaya gelmiş, Hukuk Fakültesinde öğrenim görmeye başlasa da kendini bu alanda mutsuz hissederek yazarlık yapmaya yönelmiştir. İlk romanını 18 yaşında kaleme alan yazar, 1865- 1871 yılları arasında Floransa'da yaşayarak edebiyat dünyasıyla iç içe olma olanağını elde etmiştir. Floransa'da ona yol gösterecek olan ve aynı görüşleri paylaşacağı Luigi Capuana ile tanışmış ve onunla iyi bir dostluk geliştirmiştir. 1872'den 1891 yllına kadar ise Milano'da yaşamış, orada da Praga, De Roberto gibi ünlü edebiyat eleştirmenleri ve yazarları ile bir arada olma şansını yakalamıştır. Burada dahil olduğu edebiyat ortamlarında realizm üzerine tartışmalara katılmış, Fransız natüralizmi üzerine çalışmalar yapmış, özellikle de bu akımın temsilcisi 
The research of the terms of 'death' and 'destiny' in the story named "Nedda" of Giovanni Verga, the representative of Italian realism / E. Balamir (pp. 428-435)

olan Flaubert, Zola, Balzac gibi yazarları incelemiş, akımın yavaş yavaş olgunlaşmakta olan İtalyan gerçekçiliğine etkileri üzerinde çalışmalar yürütmüştür.

Fransız natüralizminden etkilenerek İtalya'da doğan verizm yani gerçekçilik akımının yalnızca Fransız natüralizminden değil, aynı zamanda realizminden de etkilendiği bir gerçektir. Verizmin İtalya'da doğuşu son derece zorlu bir sürece denk gelmiştir. İtalya henüz ulusal bir birlik sağlamış değildi ve bunun çalışmalarını yürütmekteydi. Özellikle Güney İtalya'da yaşamakta olan yoksul, cahil ve bilinçsiz halk bu birliğin sağlanmasında engel teşkil edecek kadar toplumdan uzaktı. Yeni kurulmakta olan İtalyan Devletinin Güney İtalya'ya olan bakışı, bir bakıma yetersizliği ve karşıtllğı bölgesel farklılıkların ortaya çıkmasına sebep olmaktaydı. Güney İtalya daima geri planda kalmış, yoksulluğuna mahkûm edilmişti. Özgürlükçü, aydınlanmacı ve demokratik tüm söylemler İtalya'nın kuzeyinde gerçekleşirken, Güney İtalya ihmal edilmişti. İşte bu noktada ortaya çıkan verizm, özellikle güneyde yaşayan yoksul halkın hikâyesini ele almaya karar vermişti.

Avrupalı realist yazarlar birlik olmuş bir toplumun bilinçli gereksinimlerinin sesi iken, bizim verist yazarlarımız bilinçsiz ve yoksul, ulusal yaşam kültürüne ve onun sorunlarına yabancı bir çoğunluğun sessizliğini yorumlamak zorunda kalmışlardı. Bu nedenle yapıtları Avrupalı yazarlarınkine göre daha yalnızdır, yoksullara merhametli fakat her defasında biraz daha uzak ve karamsar bir eğilimden ibarettir. (Pazzaglia, 1988, sf. 686)

Verist yazarlar gerçeği belli bir nesnellik içerisinde, hiçbir öznel öğeye, duyguya, ideolojiye yer vermeden ifade etmeyi amaçlamışlardır. Verga, "doğal bir olay gibi kendiliğinden olup gelişmiş, yazarıyla hiçbir ilişkisi olmayan” bir romanın hayalini kuruyordu. (Pazzaglia, 1988, sf. 686)

Verizmin amacı, gerçeğin bilinmesi ve yayılması için bir araç olmak, insanlar arasında yeni bağların oluşturulduğu, var olan, sosyal yapının eleştirel bakış açısı olmak ve her tür ütopyanın dışında özgürlük ve adalet ideallerinin araştırılması için temel oluşturmaktı. Sadece belli bir kesime değil, tüm topluma hitap etmek istiyorlardı. Verist yazarların bu soğukluğunun ardında, eleştirel bir küçümseme, yanlış görüşlerin dışa vurulma arzusu ve özellikle de bir umutsuzluk ve karamsarlık hali yer almaktaydı ve tüm bunlar yine de acilen İtalyan toplumunun derinlerinde yer alan sorunları çözmek gereğini ortaya koyuyorlardı. İtalyan verist yazarlar, Fransız natüralistlerine göre daha karamsar, umutsuz ve şüphecidir. Daha çok İtalya'nın belli bölgelerini incelemeyi yeğlemişlerdir, özellikle de Güney İtalya'yı. Bütün bu bilgilerin ışı̆̆ında yazar Giovanni Verga, bir süre yaşamını sürdürdüğü Sicilya'ya çevirir bakışlarını. Sicilya’nın yoksul insanını, yaşama olan bağlılığını, sorunlarla nasıl başa çıkabildiğini, yazgıya boyun eğişini, çektiği acıları olabildiğince kendi görüş ve duygularını katmadan, objektif bir gözle aktarmaya çalışır.

Verga'nın o güne kadar kaleme aldığı eserler aslında yazarın kendi yaşadıklarının birer aktarımı değildi, Risorgimento'nun (Yeniden Doğuş) ardından İtalyan toplumunda ortaya çıkan bozulmuşluğa karşı yazarın verdiği tepkiden doğmuşlardı. Yeniden doğmakta olan İtalyan toplumunun verdiği mücadeleler sonrasında düştüğü bitkin durum, İtalyan toplumunun ahlâki ve manevi yapısında da değişiklikler yaratmaya başlamıştı. Toplum artık politikaya ve halkın sorunlarına karşı kayıtsız kalmaya başlamış, kendini dünyevi zevklerin güzelliğine bırakmış, zengin olmanın türlü türlü yollarını aramaktaydı, bu nedenle de Güney İtalya'nın yoksulluğuna karşı sessiz ve umursamaz kalmıştı. Verga ilk eserlerinde büyük şehirlerdeki ekonomik sıkıntısı olmayan kesimi gözlemlemeyi yeğlemiş, onların yaşantılarını ve toplumun yoksul kesimine oranla aslında önemsiz sorunlarını dile getirmişti. Bir süre sonra ise aktardığı bu gereksiz lüks ve sahte yaşantıların yanında hayatta kalmak amacıyla günlük ekmeğini kazanma çabası içerisinde mücadele eden insanların hikâyeleri ilgisini çekmeye başlamıştır. Bakışlarını çevirdiği Sicilya aslında doğup büyüdüğü yer olmasıyla çok da iyi tanıdı̆̆ bir bölgedir. Büyük kentlerdeki bu kaosun 
aksine sığındı̆̆ı o yoksullar dünyası toplumsal sınıflar arasındaki uçurumun gerçekçi bir bakış açısıyla gözler önüne serilmesine neden olacaktır.

\title{
3.Giovanni Verga'nın “Nedda” adlı öyküsünde ‘ölüm' ve 'kader' kavramları
}

1854 yılında meydana gelen kolera salgını nedeniyle ailesi ile birlikte Sicilya'da Vizzini'de sahip oldukları topraklara taşınmak zorunda kalan Verga bu sayede köylülerle ve yoksul insanlarla tanışma firsatını bulur. Böylece bölge insanını, bu yerleri benimser ve onları eserlerinde anlatmaya başlar. Verga bu durumu şu sözlerle aktarır:

Böylece onlara karıștım, köylülerin yaşamına: kendi yaşıtlarımdan arkadaşlarım oldu, hayatımı ve karakterimi etkilediler, yoksulluklarının ya da tutkularının dramlarına doğrudan tanık oldum; her gün gördüğüm çalışkan insanlara sevgi duyuyordum, tüm hislerimle onları anlamaya çabalıyordum. Bir süre sonra tüm bu gençlik deneyimleri capcanlı bir güçle bana geri döndüler, işte o gün bugündür onları bir araya getirmeye çalışıyorum. (Öncel, 1971, sf. 48)

“Nedda”, Verga'nın Sicilya yöresini anlattığı ilk eser olarak ve verizmin ilk izlerini taşıması açısından önem taşımaktadır. Öyküye adını veren yoksul ve zavallı bir genç kızın hikâyesinin anlatıldığı öyküde yaşamla olan mücadele, aşk, yoksulluk, ölüm ve kader motiflerinin ön plana çıktığı saptanmaktadır. Öykü 1874 yılında yayımlanır ve eleştirmenlerce Verga'nın verizmini başlatan bu öykü olmuştur.

Capuana, Nedda için şunları söyler: "Verga Nedda'yı yazdığında, belki de İtalyan romanı adına el değmemiş bir madende yepyeni bir değer bulmuş olduğunu bilmiyordu.” (Capuana, 1972, sf. 22)

Nedda, Ravanusa'lı, Etna dağı eteklerinde Pino adlı bir adamın çiftliğinde gündelikçi ve zeytin toplama işçisi olarak çalışan bir kızdır. Yazar, Nedda’yı bize şöyle betimler:

\begin{abstract}
Esmer bir kızdı, sırtına eski püskü bir elbise giymiști. Sefaletin, yalnızlı̆ın verdiği ürkek, kaba bir hal vardı üzerinde. Yoksulluk, sıkıntılar, ağır işler yüzünden kadınlığın yalnız ince görünüşü̈ değill, insan şekli de derin bir biçimde bozulmamıș olsaydı, ona güzel bir kız denilebilirdi. Saçları siyah ve dağınıktı, bir iple şöyle bir tutturulmuştu. Dişleri inci gibi beyazdı. Yüzünün çizgilerinde, gülüşünü güzelleştiren kaba bir çekicilik vardı. Gözleri siyah ve iriydi, açık mavi bir mayi içerisinde yüzüyor gibiydiler. Yoksulluğun verdiği ürkeklikle kararmış veya sürekli, mahzun bir tevekkülle aptallaşmış görünmeselerdi, insanlık kademesinin en aşağı basamağında büzülmüş duran bu yoksul kızın gözleri bir kraliçeyi kıskandıracak güzellikteydi. Muazzam yükler altında ezilmiş veya büyük çabalar yüzünden aşıı bir şekilde gelişmiş kol ve bacakları hantallaşmış ama gürbüzleşememişlerdi. (Verga, 1959, sf.7, 8)
\end{abstract}

Nedda'nın tek ailesi hasta annesidir, tüm gün yalnızca ona ilaç alabilmek için çalışmaktadır. Yaşamda başka kaygısı yoktur. Onu o şekilde evde bırakarak çalışmaya gitmek gerçekten güçtür. Ama başka çaresi yoktur, yazgısına boyun eğmek zorundadır. Koşulları onu çalışmaya zorlamaktadır, öyle ki hava şartları kötü olduğunda işe gelmesinin anlamı olmadığından üzüntü duyar, çünkü bir gün bile ücret alamamak onun hayatını altüst edebilecektir, ancak bu doğanın onu düşürdüğü durumdur, yine yapabileceği bir şey olmadığından hayatın bu adaletsizliğine boyun eğmekten başka çaresi yoktur.

Nedda son derece sessiz, pasif ve zayıf karakterde bir kızdır. Öyküde onun bu karakterini yansıtan birçok sahne mevcuttur. Örneğin işçiler paralarını alırken ilk önce erkeklere ve kavgacı kadınlara ödeme yapılır, en son Nedda gibi sessiz kişiler paralarını alırlar. Yazar bunu ifade ederken aslında karakterinin sesini daha çok çıkarması, hakkını aramayı bilmesi, haksızıklara karşı koymak için çaba sarf etmesi gerektiğini okuyucuya hissettirmeye çalışır. Oysa Nedda, yoksul olarak dünyaya geldiğinden bunun bedelini zaman zaman ödemesi gerektiğine inanmıştır, adaletsizliklere denk gelmesi ona göre çok olağan bir durumdur. 
The research of the terms of 'death' and 'destiny' in the story named "Nedda" of Giovanni Verga, the representative of Italian realism / E. Balamir (pp. 428-435)

-Ağlamış suratlı mendebur sen de! Bir de halinden şikâyet ediyorsun!

-Şikâyet ettiğim falan yok, kabahat havada, yağışlı gitti. Alacağım paranın yarısı heba oldu.

-Git Tanrı'ya şikâyet et o zaman!

-Tanrı'ya ne şikâyet edeyim! Asıl kendimden şikâyetçiyim ben, yoksul bir kız olduğum için! (Verga, 1959, sf. 12,13)

Bazı eleştirmenler Verga'nın kahramanındaki bu tutumunu "yazgıya boyun eğme" olarak yorumlarken, kimileri de "kadercilik” değil, "değiştirilemeyecek yazgı karşısında duyulan saygı" olarak nitelendirir.

İlk kez Manzoni bakışlarını toplumun alt sınıflarına çevirmiști. Ama Manzoni’de insanların Tanrıya olan inançları bir avuntu öğesi oluyordu. Kötülükler, felâketler çabuk geçen bir firtına gibiydi, ardından mutluluk geliyordu: bu dünyada ya da öbür dünyada. Verga'da ise eski Hıristiyan inancından eser yoktur; ona göre acı ve sefalet getiren kör bir kader yaşama egemen gibidir. Yoksulların, ezilmişlerin çilesine yaşamın değișmeyen ve herkes için aynı olan zorunlu bir yasası imiș gibi acıyarak bakar. Bu yasa yoksullarda kendini daha açıkça belli eder. Verga'nın kişileri üzüntü, acı ve zorluklara yakınmadan, başkaldırmadan kahramanca boyun eğerler ve bu onları yüceltir. (Öncel, 1998, sf.196)

Nedda'nın annesinin durumu iyice kötüye gider, doktor ona bir ilaç daha yazmıştır, Nedda ilacı temin edebilmek için borç alacaktır. Hasta annesi hastalığından çok kızının borçlu duruma düşmesine üzülmektedir. Nedda ise annesinin endişelenmemesini, çalışarak mutlaka borcunu ödeyeceğini söyler. Verga'nın kahramanlarında sık gözlemlenen bir durumdur bu; ne kadar muhtaç durumda olsalar da, mutlaka borçlarını ödemek için çok çalışırlar. Bu konuda oldukça gururludurlar.

Nedda'nın annesi sonraki gün ölür. Zavallı kız tek başına kalmıştır. Nedda bu acıyı sessizce, kendi içinde yaşar. Ancak bu acının yanı sıra Nedda'da huzur da görülür, çünkü annesinin ölümle kurtulduğunu, artık acı çekmediğini, cennette olduğunu düşünmektedir. Artık onun ilaç parası için çalışmak yerine kendisi için çalışabilecektir. Verga'nın yoksul kahramanında yazgıyı kabullenme ve ölümü doğal olarak görme çok sık rastladığımız bir durumdur.

Nedda annesinin ölümünden sonra hayatına devam eder ve kendisi gibi yoksul bir genç olan Janu ile tanışır. Birbirlerine âş̧ı olan iki genç soylu ve ihtiraslı aşıkların yerine, aşkın kibar inceliklerinden bihaber, saf, kaba ve hatta ilkel iki sevgili olarak çıkar bu öyküde karşımıza. Evlenmeden aşka teslim olan bu iki genci yine talihsiz bir gelecek beklemektedir. Janu sıtması olan bir gençtir ve bir gün zeytin toplarken ateşlenir, ağaçtan düşer ve ölür. Nedda ise hamiledir, ancak evlenmeden Janu'nun ölmesi Nedda'yı yapayalnız, onu toplumun dışladığı bir durumda bırakır. Bu durum, kaderin Nedda'ya yeni bir oyunudur. Hamile olduğundan Nedda'ya kimse iş vermemektedir. Elinde avucunda ne varsa harcayan kız, hastalıklı, zayıf bir kız bebek dünyaya getirir. Ne var ki, bebeğin karnını doyuracak hiçbir şeyi olmadığından o da ölür. Bebeğinin ölüsü başında diz çöken Nedda Tanrıya şöyle şükreder:

"Sevgili ölülerim, Tanrı sizden razı olsun! Benim gibi acı çekmesin diye yavrumu elimden alan ey kutsal Bakire, Tanrı senden de razı olsun!” (Verga, 1959, sf. 33)

Giovanni Verga'nın verizm akımının ilk adımlarını attığı bilinen bu öyküsünde Nedda’nın yaşamında ölümün yakasını bir an bile bırakmadığı görülmektedir. Ancak Verga'nın bu yoksul ama mağrur kahramanı başına gelenlere asla isyan etmez, aksine olanları doğal kabul ederek ayakta durmaya, yaşamaya tüm çabasıyla devam eder. Ölümlere neredeyse şükreder, çünkü o ve ailesi doğuştan yoksuldur ve sefalet çekmektedirler. Sevdiklerinin ölümü onlar için bu zavallı hayattan kurtuluş olmuştur. Onlar kendisi gibi artık acı çekmeyeceklerdir. $\mathrm{O}$ ve onun gibi insanların yaşama sadece acı çekmek için geldiklerine inanmaktadır. Bu yüzden onlar adına mutlu olur. Verga, Nedda ve yaşamını 
anlatırken içinde bulunduğu toplumun, Sicilya’nın o dönemki yoksulluğunu, ekonomik kaygıları, cahilliği, kişiler arasındaki önyargıları, acımasızlığı ve toplum içerisindeki yozlaşmayı da dile getirmektedir. Verga'ya göre ekonomik gereksinimler yoksul insanların tüm hayatlarına, isteklerine yön veren yegâne durumdur. Nedda'nın toplumun bu tutumuna ve baskısına karşı çaresiz boyun eğmesi Verga'nın gerçekçi bakışının bir örneğidir. Güçlü güçsüzü, zengin fakiri daima ezmiş, küçümsemiştir. Bu gerçeği yadsımak mümkün değildir. Nedda'nın başına gelenler karşısındaki itaatkâr tutumu da toplumca dayatılan kaderin değiştirilemezliğinin bir göstergesi sayılabilir. Nedda için yaşam acı çekmekten, kaderine boyun eğmekten başka bir şey değildir ve ölüm ise tüm bunlardan kurtulmak demektir.

"Yoksulluk büyükannesini ezmişti, annesini de ezmişti, dolayısıyla kızının da akıbeti aynı olacaktı". (Verga, 1959, sf. 8)

Öykü her ne kadar Verga'nın İtalyan gerçekçiliğini yansıttığı ilk eseri olsa da, gerçekçi yazarlarda olması beklenen objektif bakıştan biraz uzaktır. Yazar öyküye kendi duygularını eklemeden edemez. Nedda için kullanmaktan vazgeçemediği "zavallı”, "zavallıcık”, “ürkek bir kuş” gibi sıfatlar ve ifadeler ona duyduğu merhametin örnekleri olabilir.

Nedda bir yeniktir, yaşamın tüm adaletsizliklerine karşı eziklik duygusu ve bir çeşit boyun eğme Verga'nın daha sonraki eserlerinde yer alan diğer bir çok kahramanında da gördüğümüz, Nedda'da da tanık olduğumuz özelliktir.

“Tüm hayatları boyunca aralıksız çalışanlar dahi dinginliğe ve ruh huzuruna asla kavuşamazlar. Herkesin kendi acısı, içsel bir trajedisi vardır" (Öncel, 1971, sf. 112)

Verga'nın "Nedda" ile başlayan gerçekçi bakışı ondan sonra gelen diğer bazı romanlarda da karşımıza çıkmaktadır. Bu yapıtlarına en güzel örnek "Malavoglia'larédır. Romanda yine Sicilya'da balıkçlık yaparak yaşamını sağlayan bir ailenin dramı gözler önüne serilir. Yoksul aile kaderin onlara göstereceği yolda türlü türlü talihsizlikler yaşayarak yaşam mücadelesi sergilemektedir. Aile bireyleri birbirlerine son derece bağlı eski ataerkil bir ailedir. Yaşamda verdikleri bu mücadele içlerindeki dayanışma sayesinde bir nebze kolaylaşmaktadır. "Yazarın deyişine göre içlerinden her kim, herhangi bir nedenle sürüden ayrllırsa dünya onu yutuverir". (Öncel, 1998, sf.195) Roman ilerledikçe Malavoglia ailesinin bağlarının nesiller arası farklılıkların ve öncelikle kaderin getirdiklerinden ötürü zayıfladığını, ailenin reisi dede 'Ntoni'nin de ölümüyle dağılmaya yüz tuttuğuna tanık oluruz. Büyük borca girerek aldıkları baklaları bir yerden bir yere kayıkla taşıyan büyük oğul Bastianazzo fırtınada kaybolur ve ölüsü bulunur. Borcu ödemek için ellerinde ne varsa, evleri de dahil olmak üzere kaybederler. Küçük torun Lucca askerde can verir. Büyük oğul Bastianazzo'nun karısı Maruzza kolera salgınında hayatını kaybeder. Askerden dönen büyük torun 'Ntoni ise, baba mesleği olan balıkçılığa dönmek istemez ve usülsüz işlere girer, nihayetinde hapse atılır. Kız torun Lia aileden kaçar ve kötü yola düşer. Anlaşıldığı üzere bu romanda da "Nedda"da olduğu gibi kaderin çizdiği acımasız yolda yılmadan yürüyen yoksul bir Sicilya'lı aile söz konusudur. Yaşadıkları drama rağmen yaşamda kalma mücadelelerini asla kaybetmezler. Bu başkaldırısız boyun eğme onları adeta yüceltir niteliktedir.

Verga'nın çağı sosyalizmin yayılmaya başladığı ve edebiyatın da alt düzeydeki insanların sefaletine yönelttiği bir dönemdi. Ama Verga'nın kişilerinde sosyal polemik yoktur. Çünkü Verga, belirttiğimiz gibi, o aç ve güçlükler yasasının değişmezliğine inanıyordu, karamsarlığı bir yenilenme umuduna ve beklentisine yer vermiyordu. (Öncel, 1998, sf. 197)

Verga'nın insan yazgısı ve ölüm kavramlarını verist görüşleriyle bir arada yansıttı̆̆ı, söz edilmesi gereken bir başka romanı da "Mastro Don Gesualdo"dur. Roman yine Sicilya'da geçer. 
The research of the terms of 'death' and 'destiny' in the story named "Nedda" of Giovanni Verga, the representative of Italian realism / E. Balamir (pp. 428-435)

Başkahramanımız Don Gesualdo bir duvarcı ustasıdır. Çok çalışmış ve iyi para kazanmış, işinde yükselmiştir. Kendi çevresinden bir kadın onu çok sevse de gidip eski soylu bir ailenin kızıyla evlenir. Bu evlilik Don Gesualdo'nun geçmişine olan bir isyan niteliğindedir. Ancak soylu bir aile kızıyla yaptığı bu evlilik onun başına türlü felaketler getirmekten başka bir işe yaramayacaktır. Çünkü Gesualdo'nun geldiği sosyal sınıf ile soylu sınıf farkı, onun arada sıkışıp kalmasına neden olacaktır. Karısının ölümünün ardından ve ülkedeki politik durumların değişmesi ile yoksul halkın varlıklı hale gelmiş bu adama karşı başkaldırısı sonucu kızı ve damadının yanına yerleşmekte çare bulan Don Gesualdo'nun mal varlığını har vurup harman savuran evlatlarının onu adeta yapayalnız ölüme terk ettiklerini görürüz. Malavoglia'larda gördüğümüz dede 'Ntoni karakteriyle aynı kişilik özelliklerini taşıyan Gesulado dede 'Ntoni'ye göre baöbaşka bir dünyayı deneyimleme olanağı bulsa da aslında aile bağlarının güçlü olmasını dileyen bir karakterdir. Kendi koşullarında yaşamak yerine soyluların yaşamına özenerek kendi kötü kaderini yazan Gesualdo bir yeniktir, Malavoglia ailesindeki bireyler gibi.

Verga'nın dünyasında sürekli karşımıza çıkan acımasız, katı bir yazgıdır ve ona karşı verilen her mücadele gereksiz ve boştur. Ramat şöyle belirtir: "zaten belirlenmiş olan değiştirilemez" ve ekler "bu insanlar, yenik olsalar da, insanlık onurlarını dişlerini sıkarak savunurlar ve yenilgileri destansı bir mücadele sonrasında gerçekleşir” (Ramat, 1945, sf.69)

"Yazgı karşısında acı yenilgilerden başka şey yoktur, bu nedenledir ki, onu lanet okumaksızın ve de kutsal kılmaksızın, boyun eğerek kabul etmek gerekir.” (Öncel, 1971, sf. 113)

Tüm bu görüş ve eleştiriler Verga'nın karamsar bir yazar olduğunu düşündürse de, buna karşı çıkanlar da yer almaktadır: "İronik... trajiklik. Yine de tam karamsar denemez" diye açıklarken Tonelli "her şeyin kötülük, acizlik, güçsüzlük olduğu yaşamda karamsarlık, monoton ve tek taraflı bir görüş, ya da bakış açısı olduğundan, en iyisi direnmeme ve ölümdür” (Tonelli, 1927, sf.28)

\section{Sonuç}

Verga'nın yaşama bakış açısı katıdır, onun eserlerinde yansıttığı dünyada üstünlük ve neşe yoktur; onun dünyası, istekleri daha da güçlendiren ve törpüleyen bir kaderin egemen olduğu bir dünyadır; "Eşit, ağırlığınca gri, gündelik yaşamda daima var olan ve katı kurallara bağlı, az da olsa lirik, bazen de trajik, yaşamayı ve kazanmayı gerektiren varoluşun acı ihtiyaçlarının ötesinde, çok az da olsa çıkışların olduğu bir dünya”. (Momigliano, 1923, sf. 24)

Verga mütevazi insanların, acı çekenlerin daima yanında yer almayı tercih etmiştir, sosyal sınıflar arasındaki bu ayrımı, ezilenler ve ezilmeyenler, mütevazı olanlar ve olmayanlar arasındaki bu haksızlığı yok etmek için çabalar, üretir, amacı ulusal kardeşlik ve dayanışmayı canlandırmaktır. Eserlerinde dile getirmeyi istediği ahlâki değerlerin güzelliğini kendi ülke vatandaşlarına hissettirmeyi, dahası onlara unuttukları bu değerleri yeniden öğretmeyi bir borç bilir. "Yazarın sanatının büyüklüğü her zaman ve her yerde geçerli olabilecek ahlâklı bir dünyanın varlığını kapsamasındadır” (Öncel, 1971, sf. 120)

İnsanın yaşamdan ve bu dünyadan beklentisi zenginlik olmamalıdır, aksine gerçek zenginlik iyi niyetli ve dürüst olmaktan gelecektir. "Verga, benzerlerimizi sevmeyi ve merhamet etmeyi öğretir bize: dayanışma, birinin diğerine yardımı, iyi bir amaç doğrultusunda çabaların aynı amaca yönelimi ahlâki bir görevdir Verga’ya göre" (Öncel, 1971, sf. 120)

İşte tüm bu görüşlerin yerini bulduğu öykü olan "Nedda"da kahramanın yaşam bıyu karşısına çıkan olumsuzluklar ve acılar karşısında kaderine boyun eğişi Verga’nın verist bir yazar olmasından ve 
insanları örneklendirme çabasından ileri gelmektedir. Çalışmamızda da belirtildiği üzere Nedda her ne kadar kendi kaderini değiştirmek için herhangi bir çaba gösteremese de bunca üzüntü karşısında bu yoksul yaşamdan vazgeçmeyi de göze almak istemez, çünkü başka şansı yoktur. Ayakta kalabilmek ve öncelikle annesine bakabilmek için uzak yerlerde çalışmaya gider, annesinin sorumluluğunu taşımaktan kaçmaz, onu kaybettiğinde de ölümün onun kaderi olduğu görüşünü savunur, hatta ölümün hepimiz için acılardan kurtulma yolu olduğuna inandığını dile getirir. Doğduğu yer, içinde büyüdüğü aile yoksuldur, bunu olduğu gibi kabullenmelidir. Elden çalışmaktan ve ayakta durmaya çabalamaktan başka ne gelebilir ki? Yazar öyküsünde bunu defalarca dile getirmiştir. Yöre insanının hemen hemen hepsinin yazgısı budur. Yazarın doğup büyüdüğü bu yöreye çevirdiği bakışları çağının diğer tüm verist yazarlarında karşımıza çıkan bir özelliktir. Yazar bu söyleminden vazgeçmemiş, yörenin gerçeklerini diğer yapıtlarında da gerçekçi bir bakış açısıyla gözler önüne sermeye çalışmıştır. Yazarın "Nedda" ile başlayan verist görüşlerinin çoğunu makalede de yer verdiğimiz "Malavoglia'lar" ve "Mastro Don Gesualdo" adlı iki önemli romanında da yinelediğini görmekteyiz.

Yapıtlarında kendi görüşleri ve kahramanlarına yaşadıklarının karşısında duygusal bir müdahalesini görmediğimiz Verga, aslında kendi doğup büyüdüğü yörenin halkı için üzüntü duymuş, politikacıların ve sanat çevresinin dikkatini bu yörenin insanlarının acı ve yoksul yaşantısına bir an olsun çevirebilmek onun yaşamı boyunca en önemli edebi kaygısı olmuştur. İnsan yaşamı herkes için zor deneyimler ve koşullar içermektedir, ancak Verga'ya göre insan çalışarak bu koşulları, kaderini değiştirebilir ve iyileştirebilir, yeter ki cesaret etmekten ve kazanmak için çabalamaktan vazgeçmesin. İnsan ister yoksul, ister ezilen olsun, kararlı ve çalışkan olursa, yaşamı doğru biçimlendirirse ve ahlâklı bir duruş sergilerse, kaderin de, yaşamda karşılaşılabilecek tüm zorlukların da üstesinden gelebilecektir. Onca acıya, kedere ve güçlüğe rağmen Nedda'nın yapabildiği gibi.

\section{Kaynakça}

Capuana, L. (1972). Verga e d'Annunzio, Bologna: Edizioni Cappelli.

Momigliano, A. (1923). Giovanni Verga Narratore, Palermo: Gaetano Priulla Editore.

Öncel, S. (1971). Aspetto sociale ed umano dell'arte verghiana, Ankara: A.Ü. DTCF.

Öncel, S. (1998). İtalyan Edebiyat Tarihi. 2. Kitap, Ankara: Ankara İtalyan Kültür Heyeti.

Pazzaglia, M. (1988). Antologia della letteratura italiana, Vol. 3, Bologna: Zanichelli.

Ramat, R. (1945). Ragionamenti morali e letterari, Bari: Macrì.

Verga, G. (1959). Seçme Hikayeler, çev. Feridun Timur, İstanbul: Milli Eğitim Bakanlı̆̆ı, Maarif.

Tonelli, L. (1927). L'opera di Giovanni Verga, Catania: Studio editoriale moderno. 